\title{
Article
}

\section{The Influence of Three Different Digital Cement Spacers on the Marginal Gap Adaptation of Zirconia-Reinforced Lithium Silicate Crowns Fabricated by CAD-CAM System}

\author{
Gil Ben-Izhack ${ }^{1, *}+\oplus^{\mathbb{D}}$, Asaf Shely ${ }^{1,+} \mathbb{D}^{\mathbb{D}}$, Sarit Naishlos ${ }^{2,+}$, Ari Glikman ${ }^{1}$, Liad Frishman ${ }^{1}$, Avi Meirowitz ${ }^{1, \dagger}$ \\ and Eran Dolev ${ }^{1}$ (D)
}

1 Department of Oral Rehabilitation, Sackler Faculty of Medicine, The Maurice and Gabriela Goldschleger School of Dental Medicine, Tel Aviv University, Tel Aviv 6997801, Israel; asafshely@gmail.com (A.S.); ariglikman@gmail.com (A.G.); frishman.liad@gmail.com (L.F.); eintmz@tauex.tau.ac.il (A.M.); eran@drdolev.com (E.D.)

2 Department of Pediatric Dentistry, Sackler Faculty of Medicine, The Maurice and Gabriela Goldschleger School of Dental Medicine, Tel Aviv University, Tel Aviv 6997801, Israel; river554@gmail.com

* Correspondence: gil.ben.izhack@gmail.com; Tel.: +972-54-598-6343

+ These authors contributed equally to the study.

\section{check for}

updates

Citation: Ben-Izhack, G.; Shely, A.; Naishlos, S.; Glikman, A.; Frishman, L.; Meirowitz, A.; Dolev, E. The Influence of Three Different Digital Cement Spacers on the Marginal Gap Adaptation of Zirconia-Reinforced Lithium Silicate Crowns Fabricated by CAD-CAM System. Appl. Sci. 2021, 11, 10709. https://doi.org/ 10.3390/app112210709

Academic Editor: Luca Testarelli

Received: 15 October 2021

Accepted: 11 November 2021

Published: 12 November 2021

Publisher's Note: MDPI stays neutral with regard to jurisdictional claims in published maps and institutional affiliations.

Copyright: (c) 2021 by the authors. Licensee MDPI, Basel, Switzerland. This article is an open access article distributed under the terms and conditions of the Creative Commons Attribution (CC BY) license (https:// creativecommons.org/licenses/by/ $4.0 /)$.
Abstract: Background: This study compared the influence of three different radial spacers $(60,90$, 120 microns) on the marginal gap adaptation by using computer-aided manufacturing (CAD-CAM) for producing monolithic zirconia reinforced lithium silicate (ZLS) ceramic crowns. Methods: A total of 45 abutment acrylic teeth were divided into three groups of different radial spacers $(60,90$, and 120 microns). In each group 15 teeth were scanned by Omnicam intra oral scanner and ZLS crowns were ground. For each unit the marginal gap was evaluated at four regions of interest by scanning electronic microscope (SEM). To compare the marginal gap between the three groups a one-way ANOVA with post-hoc Bonferroni test was preformed $(\alpha=0.05)$. Results: The marginal gap for a 60 microns $(162.99 \pm 16.25 \mu \mathrm{m})$ radial spacer was found significantly higher than $90(41.85 \pm 3.57 \mu \mathrm{m})$ and $120(41.85 \pm 5.3 \mu \mathrm{m})$ microns radial spacers $(p<0.05)$. Between 90 - and 120-micron radial spacers no difference was obtained. $(p<0.05)$. Conclusions: A radial spacer of 60 microns showed a significantly higher marginal gap compared to 90 and 120 microns and was not clinically accepted (>120 microns). For both 90 and 120 microns the marginal gap was clinically accepted ( $<120$ microns) with no difference between the groups. The radial spacer which should be optimum for CELTRA ${ }^{\circledR}$ DUO crowns is 90 microns.

Keywords: CAD-CAM; radial spacer; digital spacer; ZLS; marginal fit; marginal gap; CEREC; marginal discrepancy; SEM

\section{Introduction}

All-ceramic restorations are well accepted in recent years due to improved esthetic and mechanical characteristics [1,2]. One of these materials is zirconia lithium silicate (ZLS), which is a metal-free material and can be used for several indications by CAD-CAM production [3].

One of the new materials for CAD-CAM technology is CELTRA ${ }^{\circledR}$ DUO (Sirona Dentsply, Milford, DE, USA), a zirconia reinforced lithium silicate. This material has a primary matrix composed from silica-based glass (58\%) with a reinforced spread of zirconia particles $(10 \%)$. Sintering is not mandatory by the manufacturer instructions but studies showed that after sintering the flexural strength is greater [3]. CELTRA ${ }^{\circledR}$ DUO has two microstructure phases; the first is metasilicate $\left(\mathrm{Li}_{2} \mathrm{SO}_{3}\right)$ and the second is orthophosphates $\left(\mathrm{Li}_{3} \mathrm{PO}_{4}\right)[4]$.

The main reason for failure of single crowns is related to microleakage which may cause caries, endodontic infection, periodontal disease, and bone resorption [5,6]. A $120 \mu \mathrm{m}$ 
limit is the upper acceptable limit in the literature, although some studies are less tolerance and set the upper limit to less than $100 \mu \mathrm{m}$ [7-9].

In the past, when using a die model for fabricating metal restorations the ideal spacer was 30-40 microns and was fit for zinc-phosphate cement $[10,11]$. Today, when fabricating restorations by CAD-CAM technology the spacer is set in the digital software according to the manufacture guidance for each material. In the CELTRA ${ }^{\circledR}$ DUO brochure there is no recommendation for the recommended radial spacer, which is one of the reasons for conducting this research.

After a comprehensive review of the literature, we were not able to find studies which compared the influence of different radial cement spacers on the marginal gap adaptation of zirconia reinforced lithium disilicate $\left(\mathrm{CELTRA}^{\circledR}\right.$ DUO). The null hypothesis was that no difference would be found between three different cement spacers.

\section{Materials and Methods}

We used 45 identical plastic teeth (FLUX 8634; Columbia Dentoform, Lancaster, PA, USA), maxillary right first molars. All were prepared by the company (with a machine) as abutments for fix partial denture with the following parameters: occlusal reduction $2.5 \mathrm{~mm}$, axial wall convergence angle of 6 degrees and shoulder type finish line $1.2 \mathrm{~mm}$. All 45 abutments were scanned with an intra-oral scanner (CEREC ${ }^{\circledR}$ AC Omnicam; Dentsply Sirona, Milford, DE, USA), and a virtual model was produced (CEREC ${ }^{\circledR}$ SW 4.6.1; Dentsply Sirona). The finish line was marked and the parameters for the virtual design were set as following: occlusal spacer: $160 \mu \mathrm{m}$, proximal contacts strength: $25 \mu \mathrm{m}$, occlusal contacts strength: $25 \mu \mathrm{m}$, dynamic contacts strength: $25 \mu \mathrm{m}$, radial minimal thickness: $1000 \mu \mathrm{m}$, occlusal minimal thickness: $1500 \mu \mathrm{m}$, margin thickness: $50 \mu \mathrm{m}$, margin ramp width: $50 \mu \mathrm{m}$, margin ramp angle: $60^{\circ}$.

All 45 abutments were divided into three groups (15 in each group) defined with three different radial spacer settings in the virtual design software as following: 60 microns, 90 microns and 120 microns. All other parameters were the same as mentioned earlier.

A total of 45 crowns were ground from zirconia reinforced lithium silicate ceramic blocks (CELTRA ${ }^{\circledR}$ DUO, Sirona Dentsply, Milford, DE, USA) by using a grinding machine (CEREC MC XL ${ }^{\circledR}$; Dentsply Sirona) (Figure 1).
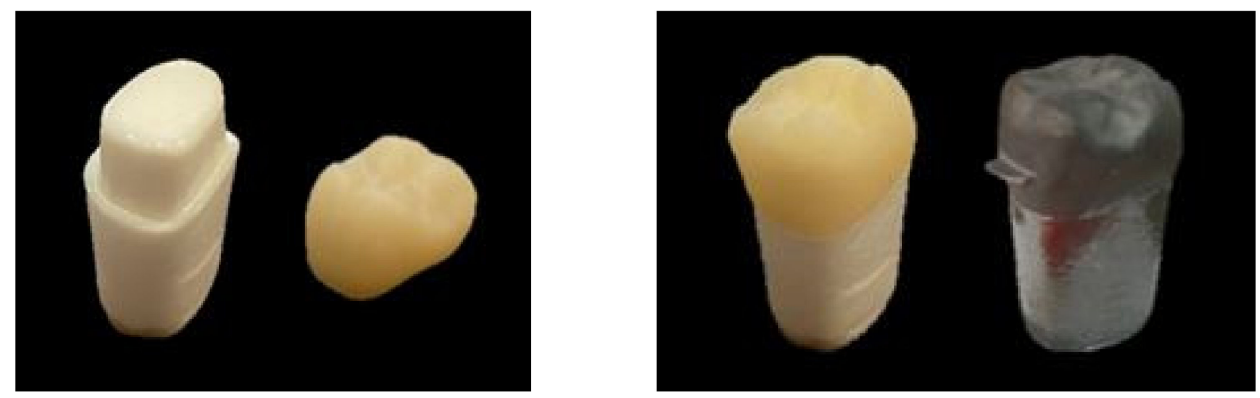

Figure 1. Plastic tooth of first maxillary molar with crown (zirconia reinforced lithium silicate) before and after gold coating.

The crowns were cemented to the abutments (unit) by using self-adhesive resin cement (Rely X U-200; 3M ESPE). During the cementation constant pressure was applied by using LUTRON ELECTRONIC ENTERPRISE CO. LTD FG-20KG which was set to $50 \mathrm{~N} \cdot \mathrm{cm}$. until setting time was completed as recommended by the manufacture.

For each unit (crown and abutment) we defined four measuring sites: Buccal, Mesial, Distal and Lingual (Figure 2). We used a new tungsten bur (FG330; Strauss\&Co, Ra'anana, Israel) on each unit to define the four repeatable reference points. For using the scanning electron microscope (SEM) a further processing was done which included a gold coating (Figure 1) of the units by using mini sputter coater (SC7620; Quorum, East Sussex, UK) for $45 \mathrm{~s}$. 


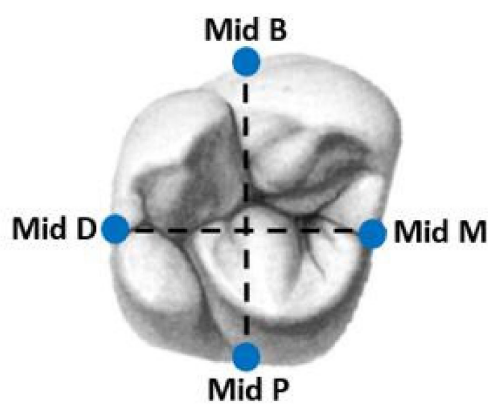

Figure 2. Four regions of interest for measurements.

The prepared units were scanned by SEM at magnification of $\times 250$ (JSM-IT100; JEOL, Switzerland) and the measurements were taken using operation software (InTouchScope) at the four regions of interest $(B, M, L, D)$ in the vertical dimension at the margin of the abutment, three times at each site (Figure 3). The average of these three measurements was calculated and defined as circumferential marginal gap (CMG). All measurements were done by the same operation. For each group (15 units), 180 measurements were done and calculated to 60 results which were defined as mean marginal gap (MMG). A total of 540 measurements were taken in all three groups.

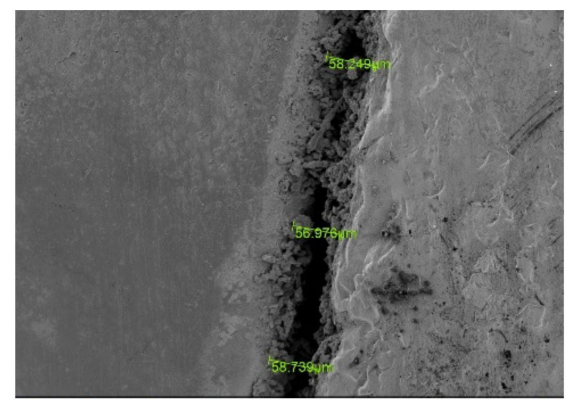

Figure 3. A side view measurement under SEM. Green line-circumferential marginal gap (CMG).

Statistical analysis was performed using the Statistical Package for Social Sciences for Windows Release 23.0 (SPSS Inc., Chicago, IL, USA).

Independent-samples one-way ANOVA test was used for the comparison of MMG. For multiple comparisons between the groups, a post Hoc test with Bonferroni correction was used. The statistical significance level for this work is $p<0.05$.

\section{Results}

The 45 units (abutment and crown) were observed and measured in four regions of interest for all three groups (Figure 3). Overall mean marginal gap (MMG) value and standard error were calculated for all three groups (Table 1). For the 60-micron spacer, the mean value was 162.99 , while for the 90 -micron spacer and the 120-micron spacer the mean value was 41.85 microns. The lowest measurement was obtained in the 120-micron group (17.85 microns) and the highest measurement was obtained in the 60-micron group (300.18 microns).

From the variance analysis between groups (one-way ANOVA; $p<0.001 ; \mathrm{F}(2,42)$ ) we reject the null hypothesis because we found that there is a difference in the MMG between groups (Figure 4). From the pair comparison (Table 2) it can be seen that there is a significant difference between the 60-micron group and the 90- and 120-micron groups, but there is no significant difference between the 90- and the 120-micron groups. 
Table 1. Mean and SE for mean marginal gap (MMG) $(\alpha=0.05)$.

\begin{tabular}{cccccccc}
\hline \multicolumn{7}{c}{ 95\% Confidence Interval } \\
\hline Spacer & Mean & SE & Lower Limit & Upper Limit & Min & Max \\
\hline $60(\mu \mathrm{m})$ & $162.99(\mu \mathrm{m})$ & $16.25(\mu \mathrm{m})$ & $128.13(\mu \mathrm{m})$ & $197.85(\mu \mathrm{m})$ & 59.22 & 300.18 \\
\hline $90(\mu \mathrm{m})$ & $41.85(\mu \mathrm{m})$ & $3.57(\mu \mathrm{m})$ & $34.20(\mu \mathrm{m})$ & $49.50(\mu \mathrm{m})$ & 25.83 & 74.73 \\
\hline $120(\mu \mathrm{m})$ & $41.85(\mu \mathrm{m})$ & $5.30(\mu \mathrm{m})$ & $30.48(\mu \mathrm{m})$ & $53.23(\mu \mathrm{m})$ & 17.85 & 99.87 \\
\hline
\end{tabular}

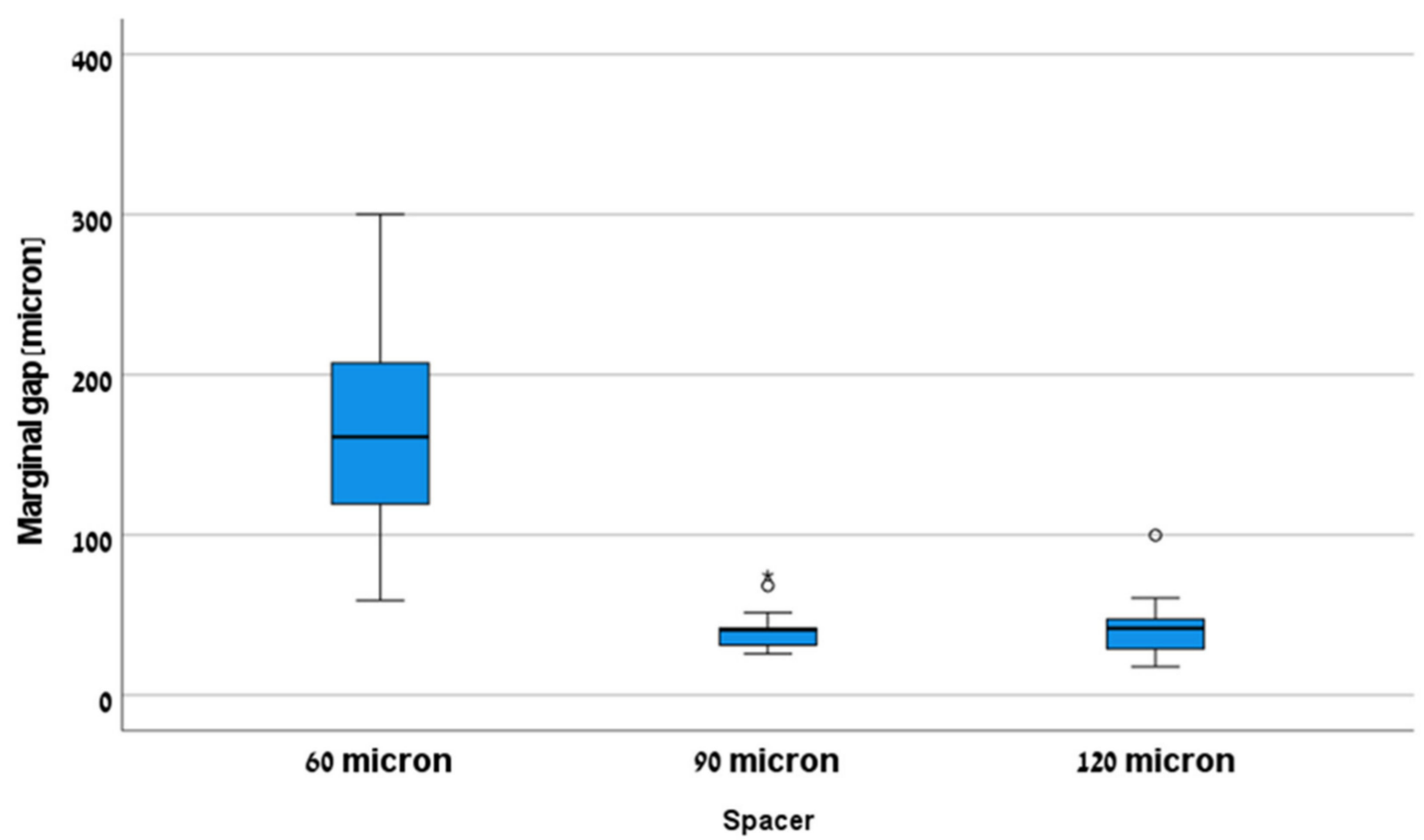

Figure 4. Box plot of all three groups.

Table 2. Multiple comparisons with dependent variable of MMG $(\alpha=0.05)$.

\begin{tabular}{|c|c|c|c|c|c|c|}
\hline \multirow[b]{2}{*}{ (I) Spacer } & \multirow[b]{2}{*}{ (J) Spacer } & \multirow[b]{2}{*}{$(\mathrm{I}-\mathrm{J})$} & \multirow[b]{2}{*}{ Std. Error } & \multirow[b]{2}{*}{ Sig. } & \multicolumn{2}{|c|}{ 95\% Confidence Interval } \\
\hline & & & & & Lower Limit & Upper Limit \\
\hline \multirow[t]{2}{*}{60 microns } & 90 microns & 121.14 & 14.26 & 0.00 & 85.58 & 156.69 \\
\hline & 120 microns & 121.13 & 14.26 & 0.00 & 85.58 & 156.69 \\
\hline \multirow[t]{2}{*}{90 microns } & 60 microns & -121.14 & 14.26 & 0.00 & -156.69 & -85.58 \\
\hline & 120 microns & 0.00 & 14.26 & 1.00 & -35.56 & 35.56 \\
\hline \multirow[t]{2}{*}{120 microns } & 60 microns & -121.13 & 14.26 & 0.00 & -156.69 & -85.58 \\
\hline & 90 microns & 0.00 & 14.26 & 1.00 & -35.56 & 35.56 \\
\hline
\end{tabular}

\section{Discussion}

Our null hypothesis was rejected, as we found that the marginal gap for a radial spacer of 60 microns $(162.99 \pm 16.25 \mu \mathrm{m})$ was significantly higher compared to a radial spacer of $90(41.85 \pm 3.57 \mu \mathrm{m})$ and $120(41.85 \pm 5.3 \mu \mathrm{m})$ microns.

Marginal fit can be measured by different methods; replica technique, micro-CT, sectional technique and direct visualization are some of these methods [8,12-15]. In our study we used the direct visualization method.

In the past, when using a die model for metal crowns, the spacer was adjusted to 30-40 microns for ideal cementation using ZPC; the frictional fit between the abutment and the crown depends on the spacer and can affect the retention $[16,17]$. Nowadays, when 
using a digital work flow the radial spacer can be set according to the material and to the manufacturer recommendations. In our study we used CELTRA ${ }^{\circledR}$ DUO and we could not find the manufacture recommendation for the ideal radial spacer. We assumed that as the radial spacer increases the marginal gap decreases.

Kale et al. examined the influence of radial spacer $(25,30,40,50$ microns) on the marginal fit of monolithic zirconia crowns and showed that as the radial spacer increases the marginal fit decreases; the lowest marginal gap was at the group of 50 microns. In this study, a stereomicroscope was used to measure the gap. We used a SEM which has a larger magnification and better accuracy. Moreover, in our study we checked higher radial spacers $(60,90,120)$ and were able to show that a radial spacer of 90 microns showed the same marginal gap as 120 microns and therefore should be set as the optimal spacer [18].

A study by Zhang et al. used lithium disilicate crowns with three different radial spacers (50, 100, 200 microns) and also showed that as the radial spacer increases the marginal gap decreases. The limitations of this research include different teeth preparations, the space gap was filled with PVS and the pressure was set by finger and not standardized using a controlled pressure machine, all of which may affect the results [19]. Similar results were obtained when using PMMA crowns with three different radial spacers $(40,50$, 60 microns) [20]. It should be noted that in our study a 60 microns radial spacer gave an unacceptable clinical marginal gap (162.99 microns) compared to an acceptable marginal gap at 50 microns that was shown in the studies by Kale and Zhang; we assume that this difference is mainly due to the cementation in our study and also due to different measurement method (stereomicroscope versus SEM) and different materials (monolithic zirconia and glass ceramic versus zirconia reinforced lithium silicate).

The improvement in marginal fit as the spacing increases is attributed to a number of factors including a decrease in the hydrostatic forces generated while the crown is cemented, an improvement in the cement flow and a decrease of friction between the crown and the abutment during the cementation. Wilson et al. suggested that increased spacing allows a better flow of excess cement and thus lowers the chance of cement particles accumulating at the margins. In addition, Grajower et al. argued that contact between irregular areas on the inside surface of the crown and the abutment may cause improper seating of the crown and may lead to increased vertical marginal fit; due to this they suggested performing spacing to avoid these contacts $[17,21,22]$.

It should be emphasized that although it has been shown from previous studies that an increase in the thickness of the radial spacer improves the marginal fit, a thickness of more than 120 microns may lower the resistance to fracture in porcelain crowns without significantly improving the marginal fit. Therefore, the optimum thickness of spacer should give us the best marginal fit without harming the mechanical properties of the material and give us the maximum retention $[23,24]$. In our study the marginal fit was the same for both 90 microns and 120 microns radial spacers, therefore 90 microns should be the spacer of choice for CELTRA ${ }^{\circledR}$ DUO without decreasing the retention and the mechanical properties of the material.

In this study there are several limitations: it is an in-vitro study, only one type of intra oral scanner was used, only one type of material was used, the crowns were not sintered which may affect the accuracy of the marginal fit, the occlusal spacer was set on 160 microns and we did not check if by changing this parameter it would affect the marginal gap, a non-standard occlusal reduction for Celtra Duo was used and we observed only 12 points for each unit.

\section{Conclusions}

With the limitations of this in-vitro study we suggest that:

1. A radial spacer of 60 microns showed a significantly higher marginal gap compared to 90 and 120 microns and was not clinically accepted (>120 microns).

2. The radial spacer for both 90 and 120 microns was clinically accepted ( $<120$ microns). 
3. The radial spacer which should be considered optimum for CELTRA ${ }^{\circledR}$ DUO crowns is 90 microns.

Author Contributions: Conceptualization, G.B.-I. and E.D.; methodology, A.M.; software, A.S. and S.N.; validation, G.B.-I., A.S. and E.D.; formal analysis, L.F.; investigation, L.F.; resources, A.G.; data curation, A.G.; writing—original draft preparation, A.S. and G.B.-I.; writing—review and editing, G.B.-I. and S.N.; visualization, A.G.; supervision, E.D. and G.B.-I.; project administration, A.M.; funding acquisition, G.B.-I. and E.D. All authors have read and agreed to the published version of the manuscript.

Funding: This research received no external funding.

Institutional Review Board Statement: Not applicable.

Informed Consent Statement: Not applicable.

Data Availability Statement: Data available on request due to restrictions, e.g.,: privacy or ethical.

Conflicts of Interest: The authors declare no conflict of interest.

\section{References}

1. Raigrodski, A.J.; Hillstead, M.B.; Meng, G.K.; Chung, K.H. Survival and complications of zirconia-based fixed dental prosthesis: A systematic review. J. Prosthet. Dent. 2012, 107, 170-177. [CrossRef]

2. Raigrodski, A.J. Concepts of design for contemporary anterior all-ceramic restorations: Advantages and limitations of new technologies and materials. J. Cosmet. Dent. 2013, 28, 46-58.

3. Lawson, N.C.; Bansal, R.; Burgess, J.O. Wear, strength, modulus and hardness of CAD/CAM restorative materials. Dent. Mater. 2016, 32, e275-e283. [CrossRef] [PubMed]

4. Belli, R.; Wendler, M.; de Ligny, D.; Cicconi, M.R.; Petschelt, A.; Peterlik, H.; Lohbauer, U. Chairside CAD/CAM materials. Part 1: Measurement of elastic constants and microstructural characterization. Dent. Mater. 2017, 33, 84-98. [CrossRef]

5. Sorensen, J.A. A rationale for comparison of plaque-retaining properties of crown systems. J. Prosthet. Dent. 1989, 62, 264-269. [CrossRef]

6. Yüksel, E.; Zaimoğlu, A. Influence of marginal fit and cement types on microleakage of all-ceramic crown systems. Braz. Oral Res. 2011, 25, 261-266. [CrossRef]

7. Suárez, M.J.; De Villaumbrosia, P.G.; Pradíes, G.; Lozano, J.F.L. Comparison of the marginal fit of Procera AllCeram crowns with two finish lines. Int. J. Prosthodont. 2003, 16, 229-232.

8. Coli, P.; Karlsson, S. Fit of a new pressure-sintered zirconium dioxide coping. Int. J. Prosthodont. 2004, 17, 59-64.

9. McLean, J.W.; Von Fraunhofer, J. The estimation of cement film thickness by an in vivo technique. Br. Dent. J. 1971, 131, 107-111. [CrossRef]

10. Cherberg, J.W.; Nicholls, J.I. Analysis of gold removal by acid etching and electrochemical stripping. J. Prosthet. Dent. 1979, 42, 638-644. [CrossRef]

11. Campagni, W.; Preston, J.; Reisbick, M. Measurement of paint-on die spacers used for casting relief. J. Prosthet. Dent. 1982, 47, 606-611. [CrossRef]

12. Riccitiello, F.; Amato, M.; Leone, R.; Spagnuolo, G.; Sorrentino, R. In vitro Evaluation of the Marginal Fit and Internal Adaptation of Zirconia and Lithium Disilicate Single Crowns: Micro-CT Comparison Between Different Manufacturing Procedures. Open Dent. J. 2018, 12, 160-172. [CrossRef]

13. Demir, N.; Ozturk, A.N.; Malkoc, M.A. Evaluation of the marginal fit of full ceramic crowns by the microcomputed tomography (micro-CT) technique. Eur. J. Dent. 2014, 08, 437-444. [CrossRef]

14. Beuer, F.; Aggstaller, H.; Edelhoff, D.; Gernet, W.; Sorensen, J. Marginal and internal fits of fixed dental prostheses zirconia retainers. Dent. Mater. 2009, 25, 94-102. [CrossRef]

15. Sulaiman, F.; Chai, J.; Jameson, L.M.; Wozniak, W.T. A comparison of the marginal fit of In-Ceram, IPS Empress, and Procera crowns. Int. J. Prosthodont. 1998, 10, 478-484.

16. Worley, J.; Hamm, R.; Von Fraunhofer, J. Effects of cement on crown retention. J. Prosthet. Dent. 1982, 48, 289-291. [CrossRef]

17. Grajower, R.; Lewinstein, I.; Zeltser, C. The effective minimum cement thickness of zinc phosphate cement for luted non-precious crowns. J. Oral Rehabil. 1985, 12, 235-245. [CrossRef]

18. Kale, E.; Seker, E.; Yilmaz, B.; Özcelik, T.B. Effect of cement space on the marginal fit of CAD-CAM-fabricated monolithic zirconia crowns. J. Prosthet. Dent. 2016, 116, 890-895. [CrossRef]

19. Zhang, Y.; Dudley, J. The influence of different cement spaces on the marginal gap of CAD/CAM all-ceramic crowns. Aust. Dent. J. 2019, 64, 167-174. [CrossRef]

20. Özçelik, T.; Yilmaz, B.; Şeker, E.; Shah, K. Marginal Adaptation of Provisional CAD/CAM Restorations Fabricated Using Various Simulated Digital Cement Space Settings. Int. J. Oral Maxillofac. Implant. 2018, 33, 1064-1069. [CrossRef] 
21. Passon, C.; Lambert, R.H.; Lambert, R.L.; Newman, S. The effect of multiple layers of die-spacer on crown retention. Oper. Dent. 1992, 17, 42-49.

22. Wilson, P.R. Effect of increasing cement space on cementation of artificial crowns. J. Prosthet. Dent. 1994, 71, 560-564. [CrossRef]

23. Grajower, R.; Zuberi, Y.; Lewinstein, I. Improving the fit of crowns with die spacers. J. Prosthet. Dent. 1989, 61, 555-563. [CrossRef]

24. Tuntiprawon, M.; Wilson, P.R. The effect of cement thickness on the fracture strength of all-ceramic crowns. Aust. Dent. J. 1995, 40, 17-21. [CrossRef] 